\title{
Case report: persistent skeletal problem!
}

\begin{abstract}
Rickets is a childhood disease that is characterized by weakening and softening of bones that ultimately leads to skeletal deformities, fractures, bone pains, delayed linear growth, sleep disorders intellectual disability.

The predominant etiology is the lack of vitamin D or defect in Vitamin D metabolism, less frequently due to defect in phosphate metabolism. Rickets is generally is cured by vitamin D supplementations and this therapy will ultimately may rectify most of the skeletal abnormalities and restore normal linear growth. Surgical correction of physical deformities is rarely needed. Some few cases don't respond to the regular doses of Vitamin D, (like our case), after decades of observations and studies to this kind of disorders lead to the knowledge of Vitamin D resistant rickets. VDRR is a rare genetic disorders of vitamin D metabolism; e.g. defect in activation or defect in Vitamin D receptors. Type 1 is a defect 1-a hydroxylase that activates $25(\mathrm{OH})_{2} \mathrm{D}_{3}$; calcidol to calcitriol $\left(1,25-(\mathrm{OH})_{2} \mathrm{D}_{3}\right)$; the biologically active vitamin, therefore the level of calcitriol is abnormally low VDDR II is the defect of target organs" resistance to calcitriol, and the calcitriol's level is abnormally high! These groups of metabolic disorders is characteristically observed in early months of life. The clinical presentations includes; rickets, hypocalcemia, hypophosphatemia, high Alkaline Phosphatase and for type II high calcitriol, secondary hyperparathyroidism. In type II is variable in severity of hormonal resistance, therefore some cases might respond to pharmacologic doses of vitamin D as shown in our case here.. But these high doses of Vitamin should be balanced against the syndrome of overdose and resultant hypercalcemia and hypercalciuria and nephrocalcinosis.
\end{abstract}

Keywords: persistent skeletal, vitamin D metabolism, VDR protein, hypophosphatemia
Volume 7 Issue 4 - 2019

Saadi JS AlJadir

Ministry of Higher Education and Scientific research , IRAQ

Correspondence: Saadi JS AI Jadir, Ministry of Higher Education and Scientific research, IRAQ, Tel +97I506620792, Email saljadir5I@gmail.com

Received: May 28, 2019 | Published: July 18, 2019

\section{Etiology}

The VDRR II is due to mutation in receptor gene, that alters the conjugation of calcitriol to VDR protein, that leads to unresponsiveness of the receptor to the biological action of calcitriol, therefore calcium and phosphates absorption from the intestine to blood stream to be deposited in bones, will be impaired and eventually pathological features of rickets, the transmission is generally autosomal recessive.

\section{Diagnosis}

Diagnosis is considered on clinical, biochemical and radiological findings. Biochemical findings are hypocalcemia, hypophosphatemia, secondary hyperparathyroidism, normal serum levels of calcidol (25-hydroxyvitamin D), elevated serum levels of calcitriol, high alkaline phosphatase. Radiological features include typical rickets and osteomalacia.

\section{Case presentation: chronic skeletal aches...!}

Case History Nov.2009 No.FH0066052, (Fujairah Hospital' Records, UAE)

a. Ali I.H.S, Male, Emirati National;

b. DOB: Nov.11.80;

c. Chief Complaint $(\mathrm{C} / \mathrm{C})$ improper walking and unsteady gait associated with remarkable muscular pains, involving most of shoulder and pelvic groups...

a. H/O Bowel symptoms, Gastritis, but no diarrhea or abnormal bowel habits...

b. He explained himself as if of years70s!

\section{Clinical impression:}

i. Muscles bulk is Normal! but shoulder \& pelvic girdles are weak; Proximal Myopathy

ii. No skeletal abnormality, no masses...

iii. No specific Neurologic deficit detected!

iv. Difficulty in standing without support with unsteadiness in walking

v. Scalp hair was coarse and skin dry

vi. Vitals were reported normal...

\section{Review; hospitals' reports}

a. Neuro-spinal Hospital (Dubai Nov.2006), managed by symptomatic \& physiotherapy no specific abnormality detected, MRI, Electro- diagnostic studies revealed negative findings...!

b. Low Back pain after the fall, subsequently investigated...! Inconclusive (American Hospital; Bangkok Thailand), Jan 2009; Physiotherapy was recommended.

\section{Investigations:}

i. On different occasions, urine calcium $24 \mathrm{hrs}$. was showed to be WNL ...P04 normal as well;

ii. No PTH reading are available!

iii. Extensive testing for neuromuscular disorders, as well as for rheumatic diseases, if any! 

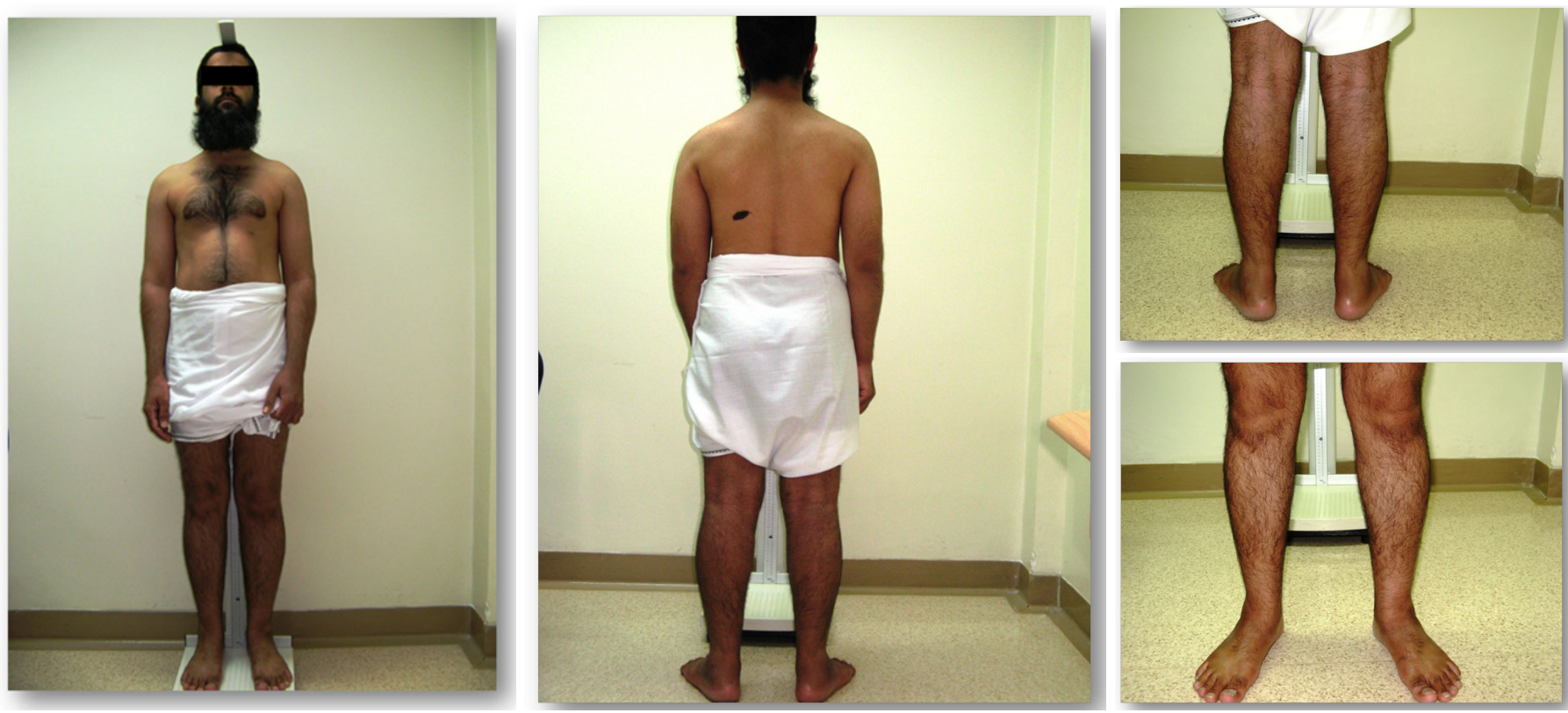

\section{Old hospital record: 1986}

a. Aug. 23

i. $\mathrm{C} / \mathrm{C}$ pains $\&$ aches 6 months, appetite is poor

ii. Hospitalized in Rashid Hospital aged 1year for inability of walking

iii. Stayed 3 months in hospital, no cause identified!

b. Aug. 26

i. X-ray of wrist; delay in ossification center, cupping \& fraying.

ii. S.Ca $\downarrow, \mathrm{Po}_{4} \downarrow$, Alk. Phos.

iii. Diagnosed as Rickets, given high dose (intramuscular) Vit. D.

c. Oct. 18

i. Review X-ray of wrist; healing started...

ii. Admission Sep.11.87

iii. $\mathrm{C} / \mathrm{C}$ inability to walk freely on getting up morning, recovered partially after last dose Vit. D on Aug.86!

iv. Looks underweight, mild bossing of forehead, knocked knee, bowed legs, chest no skeletal deformity!

v. X-ray: signs of healing rickets

vi. Still $\mathrm{Ca} \& \mathrm{Po}_{4}$ low!

vii. Given Vit. D 600,000 IU (Cholecalciferol)

viii. Admitted or managed for recurrent URT infections, childhood exanthema...

ix. Every year he used to receive same dose of Vit. D...

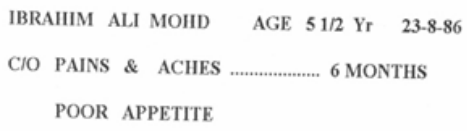




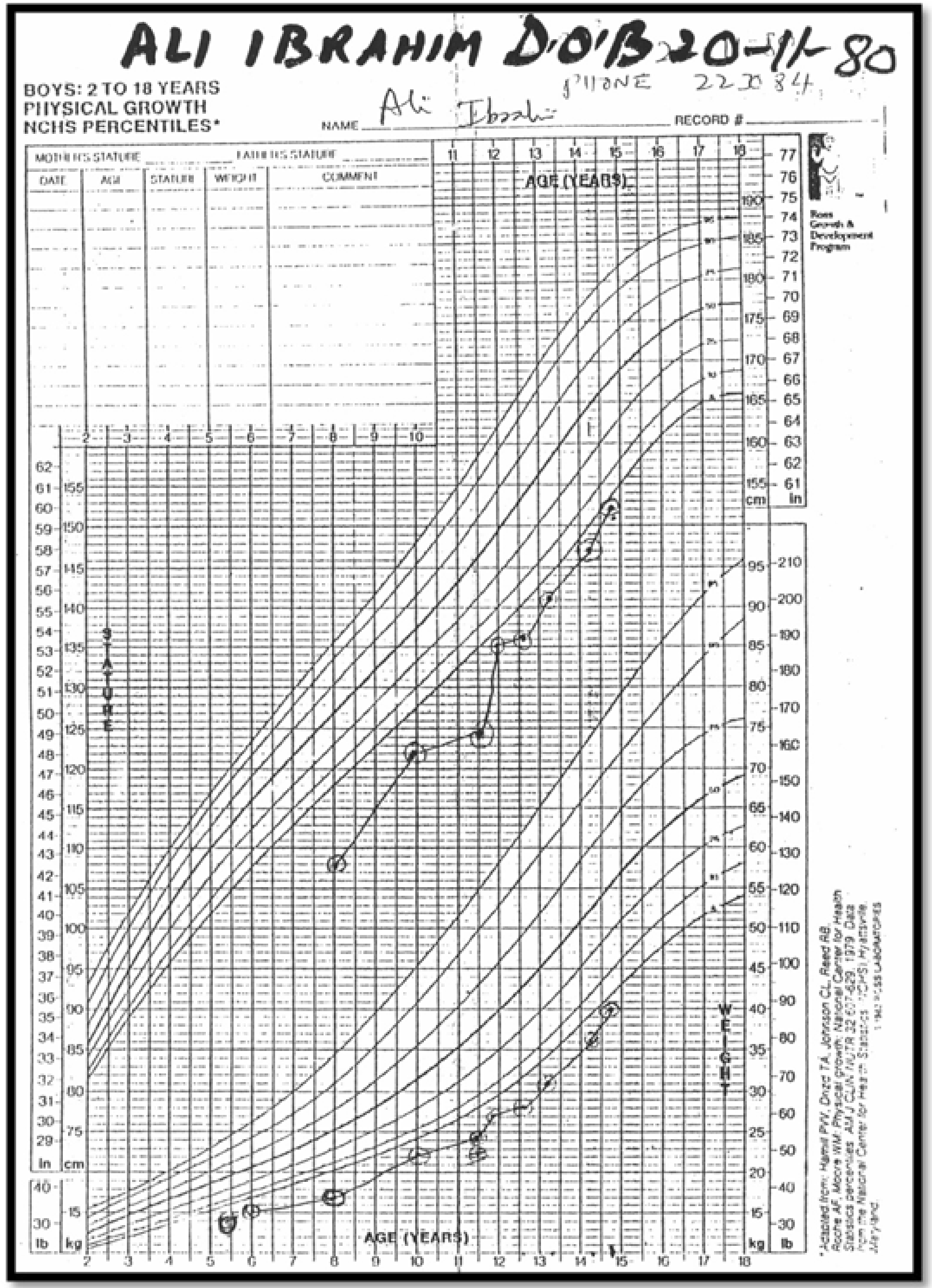



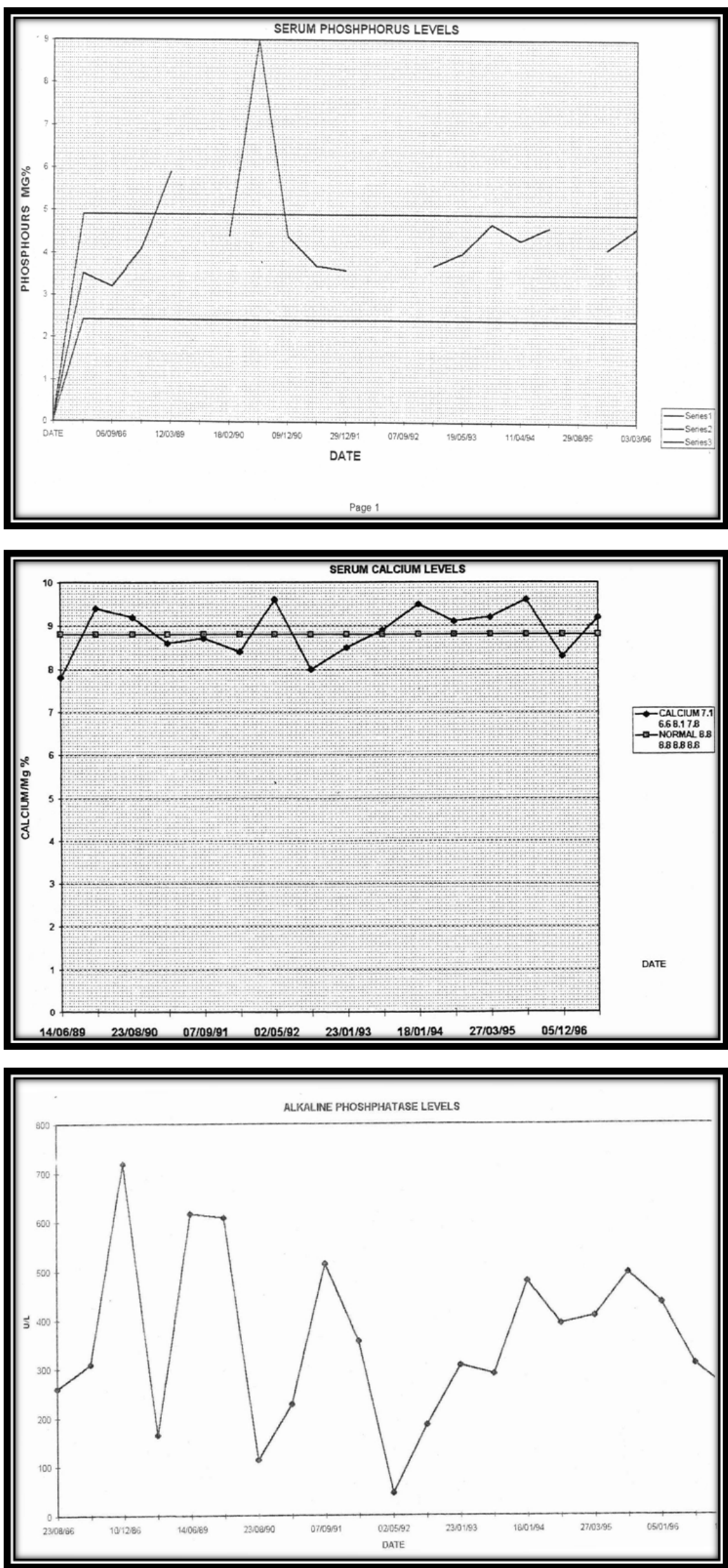

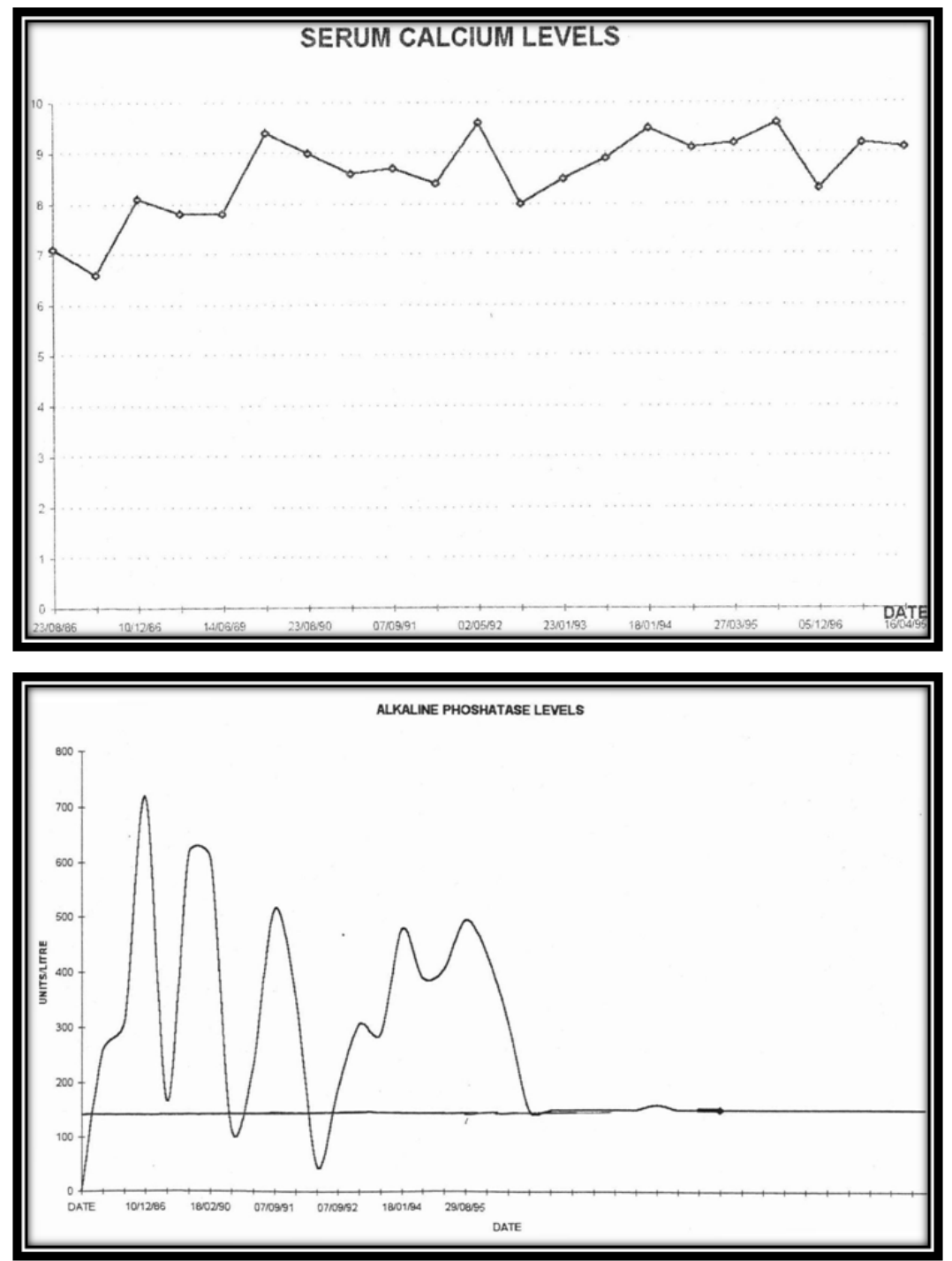

\section{X-ray on dec. 10.88}

i. Remarkable improving, bone formation is rapid and normal now!

ii. On Admission march.12.89, he was given the diagnosis of Refractory Rickets!

iii. On June ,new teeth; abnormal,weak \& brownish

iv. Same findings for $\mathrm{Ca}, \mathrm{Po}_{4}, \mathrm{Alk}$. Phosphatase.

v. On Feb. 90 sent for PTH plus others...

vi. Sample was badly handled, result inconclusive!!

\section{Skeletal events}

a. Oct.12.96: Left Radius Fracture; Coles', after a fall from height recovered without disability...

b. Aug.05.03:Headache, no specific clinical findings, CT Normal

c. Sep.2000: Gastritis and tiny ulceration of duodenum was reported by Endoscopy, managed by antibiotics and PPIs..

\section{Common causes of rickets}

I. Vitamin D Deficiency
a. Inadequate Intake
b. Malabsorptive States
c. Anticonvulsive Therapy
d. Renal diseases
e. Hepatic Diseases
f. Inadequate Renal Production of 1,25-dihydro Vitamin D

II. Excessive Renal Phosphate Loss
a. X-linked Hpophotasia (VDRK)
b. Fanconi's Syndrome
c. Lowe's Syndrome

III. Renal Tubular Acidosis 


\section{Differential diagnosis of rickets}

a. Primary Chondrodystrophy (Metaphyseal Dysplasia)

b. Hypophosphatasia; Tarda type

c. Oncogenous Rickets: Epidermal Nevus Syndrome, Neurofibromatosis

\section{Causes of vitamin D deficiency}

\begin{tabular}{ll}
\hline Defective intake or production & Low dietary intake \\
& Lack of exposure to sunlight \\
& Malabsorption \\
\hline Defective 25-hydroxylation & Liver disease \\
Defective I-hydroxylation & Renal failure \\
& Ketoconazole \\
& X-linked hypophosphatemic rickets \\
Increased metabolism & Vitamin D dependent rickets type I \\
& Phenytoin \\
Target organ resistance & Rifampicin \\
\hline Lab. results: dec.30.07 & Glutethimide \\
a. Serum Calcium $\downarrow 1.3 \mathrm{mmol} / \mathrm{L}, \downarrow 1.36$ (N 2.10-2-55) \\
b. PO4 1.08, $1.29(\mathrm{~N} 0.87-1.45)$ \\
c. ALP. $\uparrow 206,159(40-150)$ \\
$\begin{array}{l}\text { d. Electrolytes, Urea, creatinine, Albumen, LFTs; all reported } \\
\text { normal. }\end{array}$ \\
e. Bicarb 30.7, 29.6 \\
f. Serum K 3.8,3.7
\end{tabular}

\section{Lab. cct.27.09}
a. Calcium $\downarrow 1.38 \mathrm{mmol} / \mathrm{L}(2.10-2.55)$
b. PO4 $1.34 \mathrm{mmol} / \mathrm{L}(0.87-1.45)$
c. ALP $\uparrow 213 \mathrm{U} / \mathrm{L}(40-150)$
d. Bicarbonate 28.2(22-29)
e. S. Proteins Normal, Normal Albumen...

\section{Laboratory results on presentation: Nov.22.09}
a. Calcium 1.33mmol/L(N 2.10-2.55)
b. PO4 1.34mmol/L(N 0.87-1.45)
c. ALP $203 \mathrm{U} / \mathrm{L}(\mathrm{N} 40-150)$
d. LDH 267(N 100-190)
e. CPK 269(N 21-232)
f. $\mathrm{CK}-\mathrm{MB} 0.3(\mathrm{~N}$ up to 3.6$)$
g. Normal: Proteins, LFTs, Urea, Creatinine...
h. S. Na 141, CL 104
i. K 3.5 (3.5-5.3), Bicarb. $31.4(22-29)$ !

\section{Hormonal profile: nov.22.09}
a. PTH: $\uparrow 161.30 \mathrm{pg} / \mathrm{ml}(15-65)$
b. TFTs: WNL
c. FSH, LH, Prolactin; normal
d. S. Cortisol M Fasting: 11.300g/dl
e. Vit. D (25 OH) 70nmol/L (50-200)

\section{Pelvis -x-ray nov.22.2009}

$\checkmark \quad$ The Bones shows severe osteopenia, with appearance of Looser's zones in the superior pubic rami, consistent with Osteomalacia...
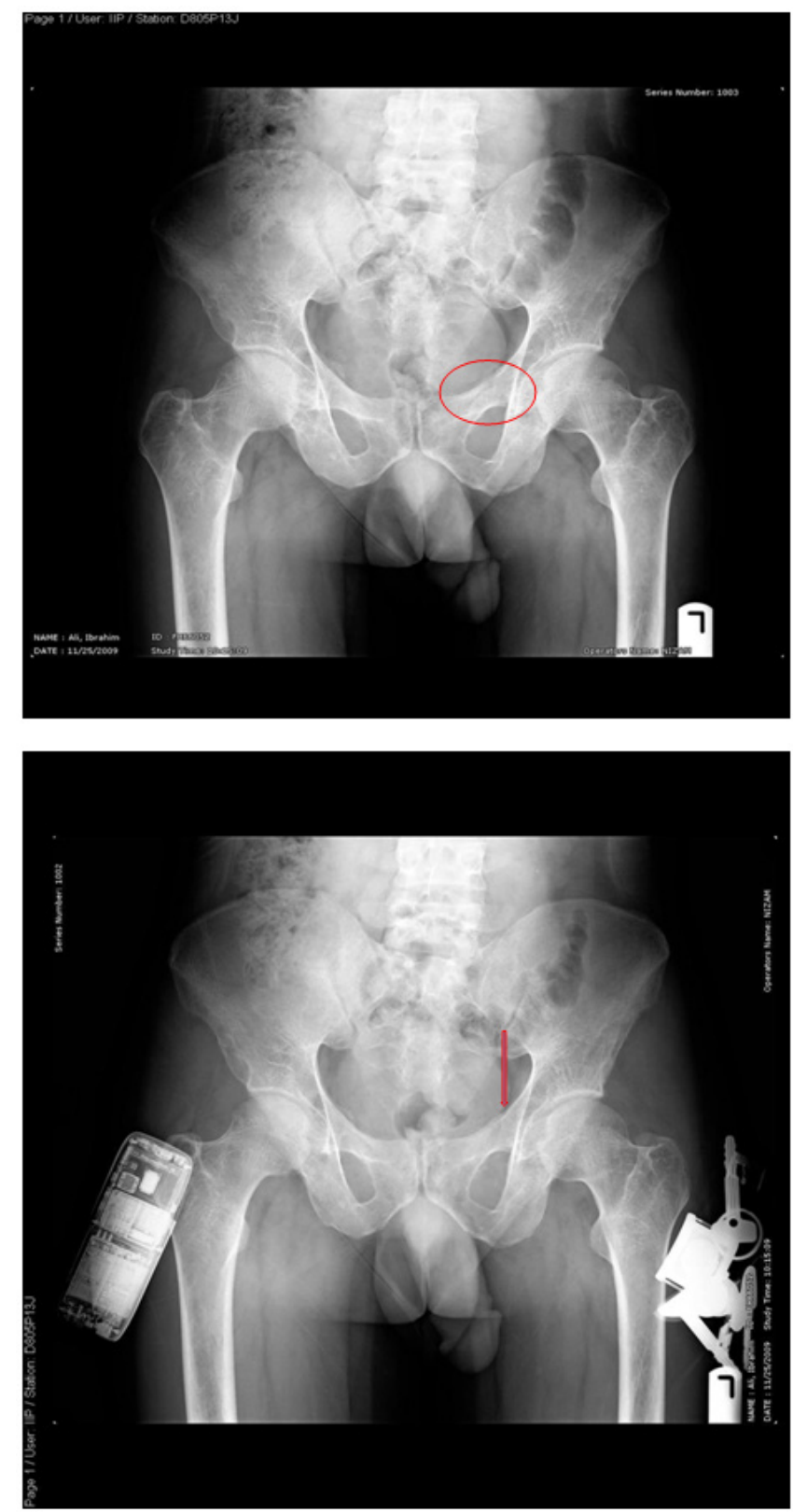

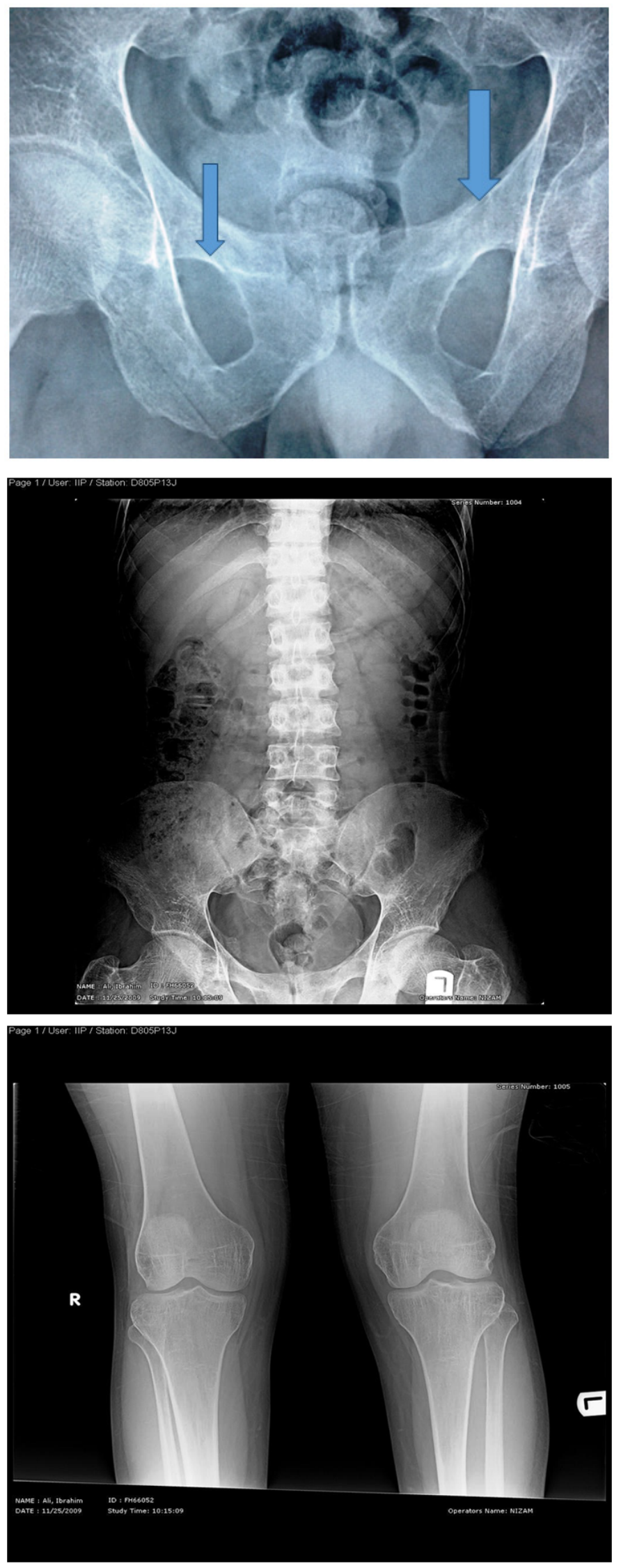

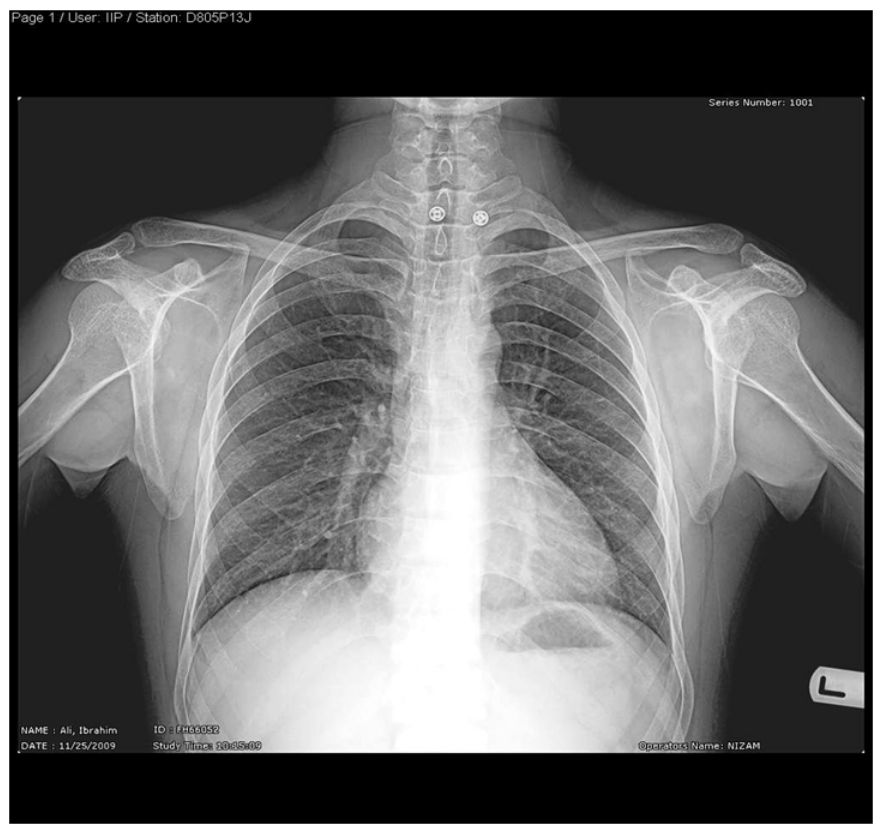

BMD: DXA nov.22.09

a. AP spine at L1-L4: $0.701 \mathrm{~g} / \mathrm{cm}^{2}, \mathrm{~T}-$ score- 4.3

b. Femur Neck: $0.543 \mathrm{~g} / \mathrm{cm}^{2}, \mathrm{~T}$-score -4.1

c. Fracture Risk is high

\section{Vitamin D}

a. Vit. $25(\mathrm{OH}) \mathrm{D}_{3}$ : 70nmol/L(50-200) nov.09

b. Ca $1.33 \mathrm{mmol} / \mathrm{L}(2.10-2.55)$

c. Vit. $25(\mathrm{OH}) \mathrm{D}_{3}: 178 \mathrm{nmol} / \mathrm{L}$

d. $\mathrm{Ca} 1.95 \mathrm{mmol} / \mathrm{L}(2.10-2.55)$

\section{Vitamin I, 25(OH)2 D3}

i. $1,25(\mathrm{OH})_{2} \mathrm{D}_{3}: 289 \mathrm{pmol} / \mathrm{L}$ (48-144), Jan.13.10

ii. Vit. $\mathrm{D}_{3} 600.000 \mathrm{U}$ given

iii. 1, $25(\mathrm{OH})_{2} \mathrm{D}_{3}$ : 66pmol/L (48-144), March 24.10, Vit. D was not given, Ca low...

\section{Calcium}

i. Vit. D given: Ca $2.11 \mathrm{mmol} / \mathrm{L}$ (2.10-2.55), Jan.05.10

ii. Vit. D given: Ca $2.30 \mathrm{mmol} / \mathrm{L}$ April.06.10

iii. $\mathrm{PO}_{4} \& \mathrm{Mg}$ were normal in all tests done...

\section{Early reports}

a. THE SYNDROME of rickets resistant to normal therapeutic doses of vitamin D but amenable to massive doses

b. It was first described by Albright, Butler and Bloomberg in 1927.

c. Until 1950, the number of known cases was approximately 30 , but increased awareness of this entity has brought the total of reported cases to over 75 . 
d. The authors 'experience with ten cases will be reviewed with emphasis on the clinical features, pathogenesis, differential diagnosis, treatment and associated congenital Anomalies...

e. California medicine

The syndrome of hereditary I, 25-dihydroxyvitamin D-resistant rickets (HVDRR)

a. (HVDRR) is a rare! Genetic disorder caused by a generalized resistance to $1,25(\mathrm{OH})_{2} \mathrm{D}$ action.

b. Heterogeneous mutations in the VDR that alter the function of the receptor are the molecular basis of HVDRR.

c. A variety of mutations have been identified, some of which render the VDR nonfunctional, imparting a complete hormoneresistant state, while other mutations reduce VDR activity, causing a hypo-responsive state.

\section{The syndrome of hereditary I, 25-dihydroxyvitamin D-resistant rickets (HVDRR)}

i. In 1978, Brooks et al., described a patient with osteomalacia who exhibited hypocalcemia, hypophosphatemia, and secondary hyperparathyroidism.

ii. Patient had markedly increased serum levels of 1, 25(OH) $2 \mathrm{D}$.

iii. Brooks et al. suggested that the rickets was due to impaired responsiveness of target organs to $1,25(\mathrm{OH})_{2} \mathrm{D}$.

iv. They had given term Vitamin D-dependent rickets type II (VDDR-II) to distinguish it from a closely related syndrome known as vitamin D-dependent rickets type I (VDDR-I)

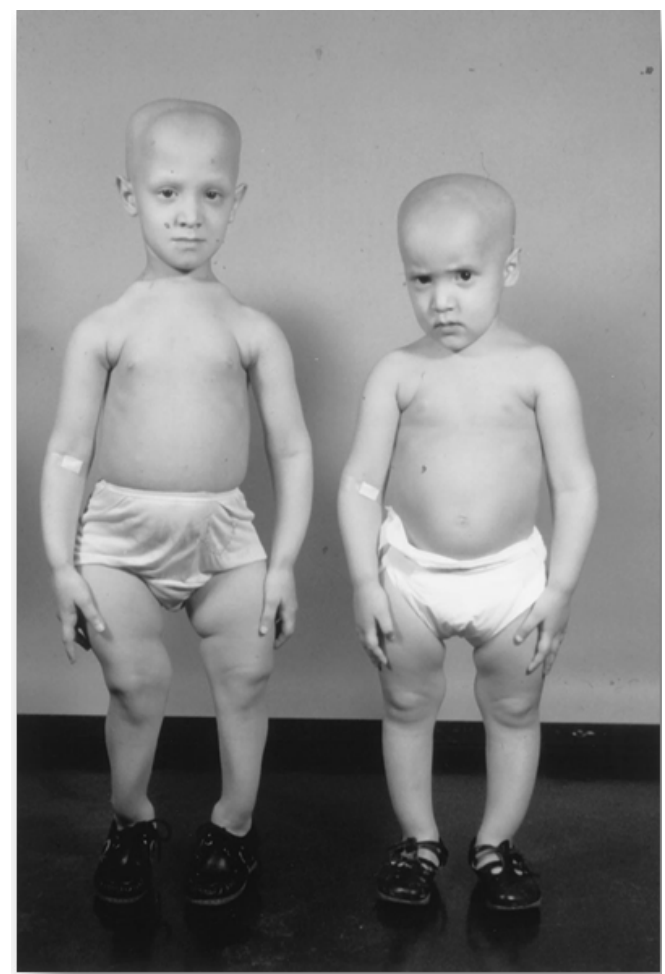

Children with HVDRR and alopecia [Reprinted with permission from J. F. Rosen et al.: J Pediatr 94:729-735, 1979VITAMIN D RECEPTOR AND HVDRR; Endocrine Reviews 20(2):156-188.

\section{Transmission}

a. HVDRR follows an autosomal recessive pattern of inheritance.

b. The recessive nature of the disease is evident from the parents who are heterozygous for the genetic trait but show a normal phenotype with no symptoms of the disease and normal bone development.

\section{Receptor defects}

i. In this rare, autosomal-recessive disorder, severe hypocalcemia and rickets develop early in childhood and are unresponsive to all forms of vitamin D.

ii. Affected persons demonstrate reduced receptor-binding capacity or defective nuclear internalization of hormone in skin fibroblasts, some also exhibit alopecia totalis.

iii. The genetic basis for dysfunctional vitamin D receptors has been identified in several affected kindred by analysis of the chromosomal gene.

iv. Point mutations in nucleotides encoding amino acids in both ligand binding and zinc finger DNA binding domains have been demonstrated.

v. Mice lacking the vitamin D receptor (VDR) develop severe hypocalcemia, defective bone mineralization, and secondary hyperparathyroidism and alopecia, a phenotype that closely resembles that seen in patients with vitamin D-dependent rickets type II.

\section{Type I}

a. 1a-Hydroxylase deficiency is an autosomal recessive disease that is manifested at an early age, presenting with hypotonia, muscle weakness, growth failure, and rickets. Hypocalcemia, elevated PTH levels, increased alkaline phosphatase activity, and low urine calcium excretion are also found.

b. Tetany and convulsions may occur with severe hypocalcemia.

c. Patients with 1a-hydroxylase deficiency have normal or elevated 25(OH)D levels but low 1,25- $(\mathrm{OH})_{2} \mathrm{D}$ levels due to various defects in the 1a-hydroxylase enzyme.

d. Patients with this condition are treated with physiological doses of $1,25-(\mathrm{OH})_{2} \mathrm{D}_{3}(0.25-2 \mathrm{mg} /$ day $)$ that bypass the defective enzyme and restore serum calcium concentrations to normal.

e. The low serum levels of $1,25-(\mathrm{OH})_{2} \mathrm{D}$ and the therapeutic response to physiological doses of exogenous $1,25-(\mathrm{OH})_{2} \mathrm{D}_{3}$ distinguish 1a-hydroxylase deficiency from HVDRR.

\section{6 months later}

a. Patient feels bright with all his previous pains and inertia had gone!

b. S. calcium monitored-dose adjustment of Vit. D;

c. 600,000 i.u Cholecalciferol Injection every 2 months is shown satisfactory.

d. Urine analyses were clear

e. ALP, $\mathrm{PO}_{4}$ serials were WNL. 


\section{Normal loading value}

The cholecalciferol loading dose required to reach the serum $25-$ $\mathrm{OHD}_{3}$ target level of $75 \mathrm{nmol} / 1$ can be calculated as follows: dose (IU) $=40 \mathrm{x}\left(75\right.$-serum $\left.25-\mathrm{OHD}_{3}\right) \mathrm{x}$ body weight.

\section{Skeletal X-Ray: 6 months later}

a. Pelvis \& both Femori: there is thickening of secondary bone trabeculae, in the neck and metaphysis of both femori indicating osteopenia

b. Upper Limbs \& legs: normal cortical thickness but there is also thickening of secondary bone trabeculae in the distal tibia and fibula

c. No Looser's zones were detected.

\section{Follow up: I 2.05.10}
a. Normal Ca 2.19 (2.10-2.55)
b. $\mathrm{PO}_{4}, \mathrm{Mg}, \& \mathrm{ALP}$
c. PTH $75.79 \mathrm{pg} / \mathrm{ml}(15-65)$

\section{PTH recent study: oct. 10}
i. Intact PTH 78.76pg/ml (15-65)
ii. Normal Ca \& Po4 urine excretion (24hrs. Sample $1350 \mathrm{ml}$ )
iii. Ca $1.9 \mathrm{mmol} /$ day $(2.5-7.5)$
iv. Po4 $14.1 \mathrm{mmol} /$ day $(12.9-42.0)$
v. Ultrasound of Kidney: no stones...
vi. Urine analysis frequently clear

\section{Conclusion}
a. Persistent $\uparrow \mathrm{PTH}$; modest!
b. Normal ca \& Po4
i. Vitamin D Dose Review Vit.D3 (Cholecalciferol Inj.)
c. Dose of 750,000 is started
d. Ca \& Po4 remained normal
e. PTH 5.69pmol/L (1.6 -6.9)

\section{Final diagnosis}

\section{Vitamin D resistant rickets; Type II}

Genetic Mutation on 1, $\alpha-25(\mathrm{OH}) \mathrm{D}_{3}$ Receptors

Or less likely!

$1, \alpha$ Hydroxylase is not fully functional ...

\section{Interpretation}

Our case exhibited many of the classic clinical (bowed legs, widening of wrists and ankle joints, while growing older he had showed looser' zones in particular sites...) and biochemical features of with markedly raised serum alkaline phosphatase; normal 25-hydroxyvitamin D; and strikingly raised 1, 25-dihydroxyvitamin! (Calcitriol, which needs special assay and expensive), In view of the striking increases in serum 1,25-dihydroxyvitamin D and the absence of evidence of poor nutrition, gastrointestinal malabsorption or clinical or biochemical evidences of hepatic or renal disease, we attribute the clinical findings in our patient to impaired responsiveness of target organs to $1,25\left(\mathrm{OH}_{2} \mathrm{D}_{3}\right)$. Hypocalcemia , secondary hyperparathyroidism have been corrected by the pharmacological doses of Cholecalciferol, after months of adjustment we could rectify all the biochemical abnormalities by 750-900,000 IU bi-monthly , two questions have to be answered: the syndrome of probable hypercalcemia and hypercalciuria that the patient might be inflicted, which logically mandates vitamin analog which has similar biological effects on skeleton with least hypercalcemic effect, second how we can differentiate between receptor defect and non-functional calcitriol..$^{2-15}$

\section{Acknowledgments}

None.

\section{Conflicts of interest}

The author declares that there are no conflicts of interest.

\section{Funding}

None.

\section{References}

1. Litman NN, Ulstrom RA, Westin WW. Vitamin D resistant rickets. Calif Med. 1957;86(4):248-253.

2. Carlsson A, H0lliunger G. The effect of vitamin D on the citric acid metabolism. Acta Physiol Scand. 1954;31(4):317-333.

3. Chisolm JJ, Harrison HC, Eberlein WR, et al. Amino-aciduria, hypophosphatemia, and rickets in lead poisoning; study of a case. $A M A$ Am J Dis Child. 1955;89(2):159-168.

4. Coleman EN, F00te JB. Craniostenosis with familial vitamin-D-resistant rickets. Br Med J. 1954;1(4861):561-562.

5. Fishman WH. Methionine-induced amino-aciduria in vitamin D resistant rickets. Metabolism. 1955;4(2):107-109.

6. Imerslund O. Craniostenosis and vitamin D resistant rickets. Acto Paediatr. 1951;40(5):449-456.

7. Jonxis JH. Amino-aciduria and rickets. Helv Paediatr Acta. 1955;10(12):245-257.

8. Jonxis JHP, Smith PA, Huisman THJ. Rickets and aminoaciduria. Lancet. 1952;2(6743):1015-1017.

9. Saville PD, Nassim JR, Stevenson FH, et al. The effect of A.T. 10 on calcium and phosphorus metabolism in resistant rickets. Clin Sci. 1955;14(3):489-499.

10. Van Creveld S, Arons P. Transitory renal osteoporosis with aminoaciduria and development of a hypersensitivity to vitamin D. Ann Paediatr. 1949;173(5):299-313.

11. Yendt ER, Howard JE. Studies on the mode of action of citrate therapy in rickets. Bull Johns Hopkins Hosp. 1955;96(3):101-115.

12. Albright F, Butler AM, Bloomberg E. Rickets resistant to vitamin D therapy. AJDC. 1937;54:529-547.

13. Sahay M, Sahay R. Rickets-vitamin D deficiency and dependency. Indian J Endocrinal Metab. 2012;16(2):164-176. 
14. Fraher LJ, Karmali R, Hinde FR, et al. Vitamin D-dependent rickets type II: Extreme end organ resistant to 1,25 dihydroxyvitamin $\mathrm{D}_{3}$ in a patient without alopecia. Eur J Pediatr. 1986;145(5):389-95.
15. Lips P. Vitamin D related disorders in primer on the metabolic bone disease and disorders of mineral metabolism. In: Rosen CJ, et al. editors. $7^{\text {th }}$ edition. Washington: ASBMR. 2013;329-35. 